\title{
DE CAPA A SPIELBERG: UMA ESTÉTICA PARA A REPRESENTAÇÃO DA GUERRA
}

\author{
FROM CAPA TO SPIELBERG: AN AESTHETIC FOR WAR \\ REPRESENTATION
}

\section{DE CAPA A SPIELBERG: UNA ESTÉTICA PARA LA REPRESENTACIÓN DE LA GUERRA}

\author{
Maikon Nikken Matuyama \\ Especialista em Fotografia pela \\ Universidade Estadual de Londrina. \\ mk.matu@gmail.com \\ Maria Luisa Hoffmann \\ Professora convidada na \\ Especialização em Fotografia da \\ Universidade Estadual de Londrina. \\ maluhoffmann@usp.br
}

\begin{abstract}
Resumo
Este estudo aborda a utilização das fotografias de Robert Capa como fonte para a criação de cenas do filme "O resgate do soldado Ryan" de Steven Spielberg, produzido em 1998. Robert Capa acompanhou o desembarque das primeiras tropas aliadas no litoral da Normandia, no dia 6 de junho de 1944, o dia D. A pesquisa indica que as cenas do filme buscam, através de técnicas cinematográficas, reproduzir a estética das imagens de Capa, fazendo com que o espectador se sinta, assim como o fotógrafo, dentro do campo de batalha.
\end{abstract}

Palavras-chave: Cinema. Fotojornalismo. Robert Capa.

\begin{abstract}
This article focuses on the use of Robert Capa's photographs as a source to create the scenes in the movie "Saving Private Ryan" from Steven Spielberg, produced in 1998. Robert Capa accompanied the first Allied troops landing on the coast of Normandy on June 6, 1944, the D day. Research indicates that the movie scenes tried to recreate, through cinematic techniques, the aesthetics of Capa's images, making the viewer feel as well as the photographer, in the battlefield.
\end{abstract}

Key words: Cinema. Photojournalism. Robert Capa.

\section{Resumen}

Este artículo trata sobre el uso de fotografías de Robert Capa como fuente para la creación de escenas de la película "Rescatando al soldado Ryan" de Steven Spielberg, producida en 1998. 
Robert Capa acompañaba las primeras tropas aliadas que aterrizaron en la costa de Normandía el 6 de junio de 1944, el día D. Las investigaciones indican que las escenas de la película, a través de técnicas cinematográficas, buscan reproducir la estética de las imágenes de Capa, haciendo que el espectador se sienta así como el fotógrafo, en el campo de batalla.

Palabras-clave: Cine. Fotoperiodismo. Robert Capa.

\section{INTRODUÇÃO}

Ainda que o termo "guerra", no sentido estrito, refira-se à confrontação violenta entre dois ou mais exércitos, o certo é que as batalhas não se desenvolvem sempre no chamado "campo de honra", mas também em terrenos não menos respeitáveis como o da mídia: pelo rádio, pelo cinema e pela televisão. Comentar o cinema de guerra, pois, é falar também do cinema como veículo de ideias políticas, econômicas e sociais.

Pretende-se com este artigo, analisar aspectos da montagem da cena do filme " $\mathrm{O}$ resgate do soldado Ryan" que retrata a chegada dos soldados americanos na Normandia no dia 6 de junho de 1944, dia que ficou conhecido como o dia D, e que foi acompanhada pelo fotógrafo correspondente de guerra Robert Capa. As imagens produzidas pelo fotógrafo no dia do desembarque das tropas aliadas na praia Omaha contribuíram na construção das cenas do filme, e com base nesse suporte documental, e através de elementos cinematográficos como a montagem, enquadramentos, ângulos, movimentos de câmera, cenários, luz e cor, buscou-se reconstruir um momento histórico e a estética do conjunto de fotografias.

\section{O FOTÓGRAFO ROBERT CAPA}

$\mathrm{O}$ fotojornalismo tem seus primeiros registros no século XIX, mas foi no século XX, a partir da Primeira Guerra Mundial, que começou a ter destaque. A partir da Segunda Guerra Mundial (1939-1945), não apenas melhorou a qualidade das imagens como aumentou sua circulação, e os registros dos conflitos e dos cenários de horror, que até então estavam distantes, passaram a fazer parte da vida do cidadão comum.

Aclamado pela revista britânica Picture Post em 1938, ainda aos seus 25 anos, como melhor fotógrafo de guerra de todos os tempos, Robert Capa presenciou a transição técnica e estética das fotografias dos grandes conflitos bélicos da primeira metade do século XX. Mais que isso, foi prova da ascensão do poderio bélico de extrema direita e viu na fotografia uma possibilidade de modus vivendi e de engajamento, atrelado ao seu posicionamento político. Acreditava que, por meio de seu filtro da realidade (a câmera fotográfica e a perspectiva de seu olhar), poderia influenciar a sociedade internacional em favor de um pacifismo, já 
incipiente nas produções culturais da época e, quando da inevitabilidade de um conflito armado, seu posicionamento político claro inspirava essa mesma sociedade em favor da obtenção da justiça (WHELAN, 2000, p. 10).

Robert Capa esteve no front das piores guerras e chegou mais próximo dos fatos do que qualquer outro fotógrafo havia ousado até então. Munido de coragem requerida pela proximidade, agregava-se um impressionante senso de composição e, principalmente, um olhar de enternecedora humanidade. Para Kossoy (1989, p. 33), "toda fotografia é um testemunho segundo um filtro cultural, ao mesmo tempo que é uma criação a partir de um visível fotográfico". O conjunto de Capa resultou nos espetaculares "momentos fotográficos", que, além de serem representações artísticas de maior iminência da verdade, trouxeram consigo indícios sobre os fatos.

Durante a Segunda Guerra, e com a ocupação nazista de Paris, Capa refugiou-se na América. Porém, com a entrada dos Estados Unidos na guerra, foi considerado um "inimigo" pelo fato de ser húngaro. Desalentado, ele recorreu a todos os meio legais, explicando ao governo sua posição e sua disposição para lutar contra os nazistas. Ele relatou sua ansiedade em um trecho de seu livro.

\footnotetext{
$\mathrm{Na}$ manhã em que eu deveria embarcar, ainda havia quatro ou cinco permissões faltando. Minha mãe, que agora vivia em Nova York, me acompanhou, e, enquanto eu tentava conseguir esses últimos papéis selados, ela esperava no táxi. Cada vez que eu voltava, ela me olhava em silêncio e tentava ler a resposta em meu rosto. Era uma mãe muito dividida naquela manhã, esperando que, pelo meu bem, eu fosse conseguir as várias permissões para ir embora; no fundo de seu coração materno, rezando para que alguma coisa desse errado e eu não pudesse partir para a guerra outra vez (CAPA, 2010, p. 34).
}

Capa se engajou então como o primeiro correspondente de guerra a desembarcar no primeiro grupo a chegar à praia da Normandia no dia D. "Eu sou um jogador. Resolvi ir com a Companhia e na primeira leva" (CAPA, 2010, p. 183).

\section{O DIA D}

$\mathrm{O}$ dia $\mathrm{D}$ foi um dos momentos mais importantes do século $\mathrm{XX}$. O plano era desembarcar em cinco praias ao longo de uma faixa de $100 \mathrm{~km}$ da costa da Normandia, Lucena até a península de Cotentin, onde as defesas alemãs do muro do atlântico eram mais frágeis. À meia noite de 5 de junho de 1944, planadores ingleses e dakotas abarrotados de paraquedistas britânicos, americanos e canadenses, entraram silenciosamente terra a dentro 
sobre a região de Normandia. Os paraquedistas foram os primeiros a pisar no solo da França ocupada, e sua missão era proteger os flancos da zona de desembarque. Ambrose (2005, p. 139-140) detalha minuciosamente o plano do dia D.

Para eles a muralha atlântica era formidável mas de modo algum inexpugnável. No dia 7 de abril, sexta-feira da Paixão, o $21^{\circ}$ Grupo de Exército tinha concluído o esboço geral do plano e estava pronto para apresentá-lo aos comandantes de Divisão, dos Corpos e de Exército. Montgomery presidiu a reunião no seu quartel general, em St. Paul's School. [...] Em Omaha, as $1^{\text {a }}$ e $29^{\text {a }}$ Divisões deviam deslocar-se para as saídas, tomar as aldeias de Colleville, St.-Laurent e Vierville, e em seguida investir para o interior. [...] Nessa reunião, Montgomery agia na suposição de que desembarcar na praia não era problema. O que o preocupava era permanecer na praia (AMBROSE, 2005, p. 139-140).

A frota aliada foi a maior armada já reunida, quase 5 mil navios de desembarque e embarcações de ataque que não foram detectados pelos alemães, pois estavam impossibilitados de fazer vôos de reconhecimento devido as péssimas condições atmosféricas. Bombardeios e artilharia pesada dos encouraçados atingiram a costa, mas erraram completamente seus alvos na praia de Omaha, e os bankers alemães permaneceram intactos.

Fazia parte das tropas americanas o escritor Ernest Hemingway que foi correspondente de guerra. Ele escreveu:

[no] dia em que tomamos a praia de Fox Green foi o 6 de junho de 1944, e o vento estava soprando forte de noroeste. Enquanto avançávamos rumo à praia na cinzenta luz do amanhecer, balsas de 10 metros em formato de caixão eram golpeadas por sólidos cobertores de água verde, que caíam nos capacetes dos soldados colocados ombro a ombro na dura, desconfortável e solitária companhia de homens que rumam à batalha (HEMINGWAY, 1944, s/p).

Os barcos Higgins que conduziam a primeira leva de equipes de assalta deviam permanecer atrás deles, mas eles eram tão lentos que os patrões, dirigindo as embarcações, os ultrapassaram. Dessa maneira a Companhia E do $2^{\circ}$ Batalhão, $8^{\mathrm{a}} \mathrm{RI}, 4^{\mathrm{a}}$ Divisão, foi a primeira companhia aliada a atingir a praia na invasão. A corrente marítima, correndo do norte para o sul, tinha levado suas embarcações a uma distância maior à esquerda, de modo que eles acabaram um quilômetro ao sul de onde deviam ter chegado (AMBROSE, 2005, p. 334).

Foi em meio a toda essa hostilidade que Capa eternizou as imagens que mostram os soldados aliados, no dia $\mathrm{D}$, alcançando a praia em meio à arrasadora barreira de fogo dos inimigos alemães. Para conseguir o ângulo de tomada, o fotógrafo teve de virar as costas para 
os tiros. Mais de dois mil soldados perderam suas vidas no desembarque. Com o movimento das ondas eles ficaram encurralados entre o mar e o fogo das armas das casamatas alemãs.

Figura 1 - Primeira leva de tropas americanas desembarcando no dia D, Praia “Omaha”, perto de Colleville-surMer, costa da Normandia

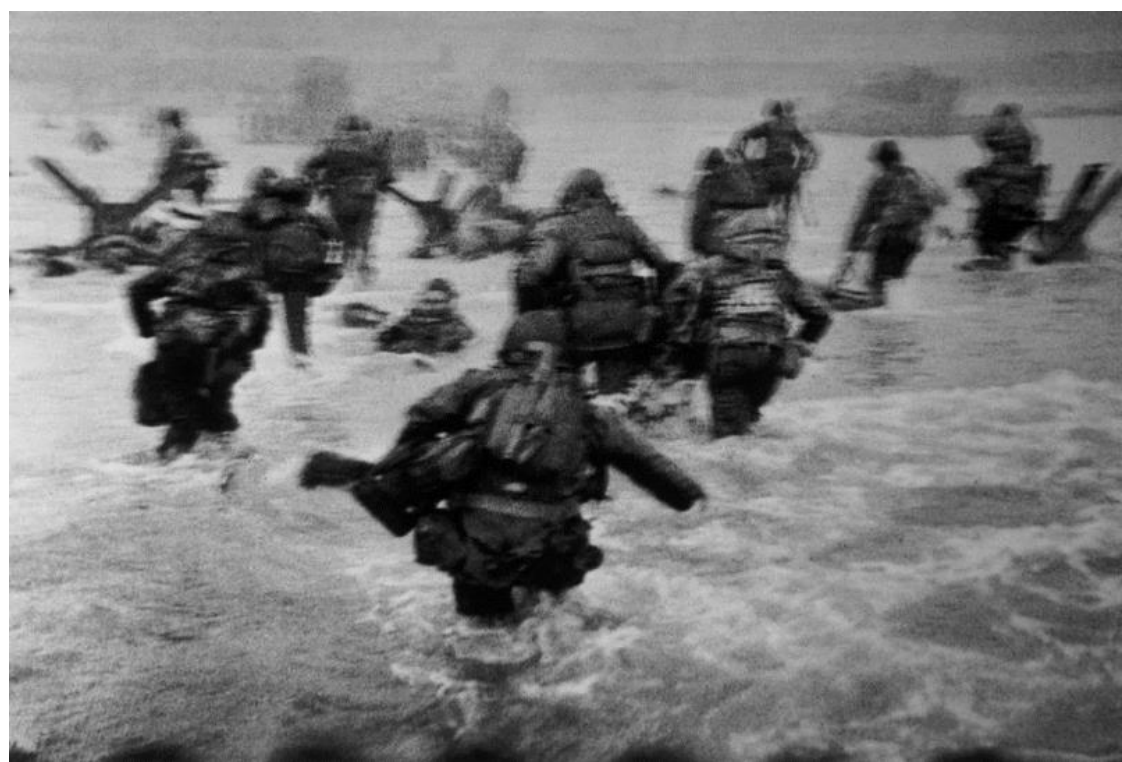

Fotografia: Robert Capa, 1944

Fonte: Magnum Photos. Disponível em:<http://www.magnumphotos.com>. Acesso em: 18 set. 2012.

Ali, em 6 de junho de 1944, era a praia mais feia de todo o mundo. Exaustos pela água e pelo medo, estávamos deitados de bruços na estreita faixa de areia molhada entre o mar e o arame farpado. A inclinação da praia nos dava alguma proteção das balas de metralhadoras e rifles, contanto que ficássemos deitados, mas a maré nos empurrava para o arame farpado, onde estava aberta a temporada de caça para os atiradores (CAPA, 2010, p. 187-193). 
Figura 2 - Primeira leva de tropas americanas desembarcando no dia D, Praia “Omaha”, perto de Colleville-surMer, costa da Normandia

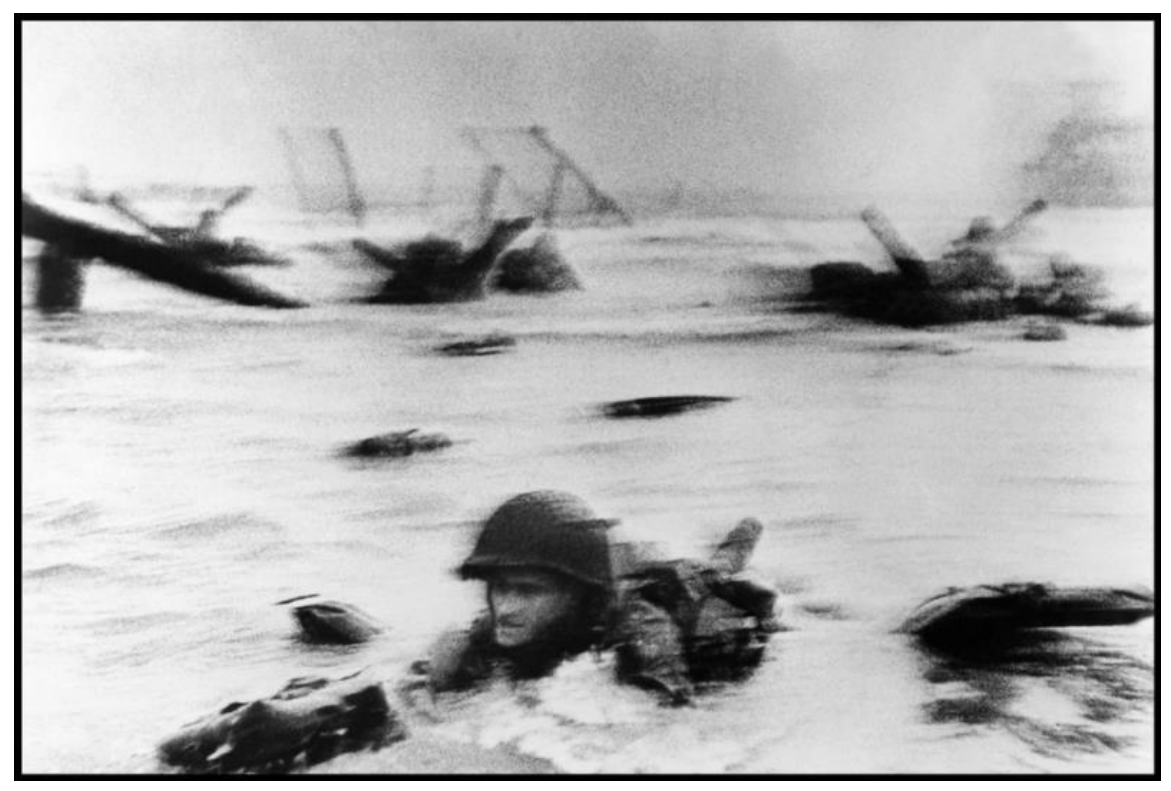

Fotografia: Robert Capa, 1944

Fonte: Magnum Photos. Disponível em:<http://www.magnumphotos.com>. Acesso em: 18 set. 2012.

Ao final, a guerra ceifaria a vida de 60 milhões de pessoas. Nunca antes ou depois houve outra operação que se comparasse ao Dia D, mais por sua complexidade que por seus números absolutos. Desembarcar soldados e tanques em praias tomadas pelo inimigo é algo tão difícil que ainda hoje é evitado a qualquer custo. E foi nesse ambiente que Robert Capa deu expressão ao sofrimento, sua câmera captava e fazia perdurar a emoção.

\section{O RESGATE DO SOLDADO RYAN (1998)}

O filme "O resgate do soldado Ryan" recria a invasão do dia D, quando o Capitão John H. Miller, comandante da Companhia Charlie, pertencente ao do $2^{\circ}$ Batalhão dos Rangers, sobrevive ao desembarque na praia de Omaha na costa da França e forma um grupo de soldados para penetrar nas defesas alemãs, levando à tomada da praia.

Três dias após a invasão, o capitão Miller recebe a missão de encontrar e resgatar o soldado James Francis Ryan, caçula de quatro irmãos, dentre os quais três morreram em combate. Ele forma uma esquadra (pequeno grupo militar) de oito homens e parte para cumprir sua missão. O soldado Ryan, paraquedista, deveria estar próximo da cidade de Neuville, mas não havia certeza pois a maior parte dos paraquedistas foi levada a saltar nos locais errados e muitos foram perdidos. 
Figura 3 - Cenas iniciais do filme "O resgate do soldado Ryan", desembarque na Normandia, no dia D Fotografia: Maikon Matuyama, 18 de set. de 2012

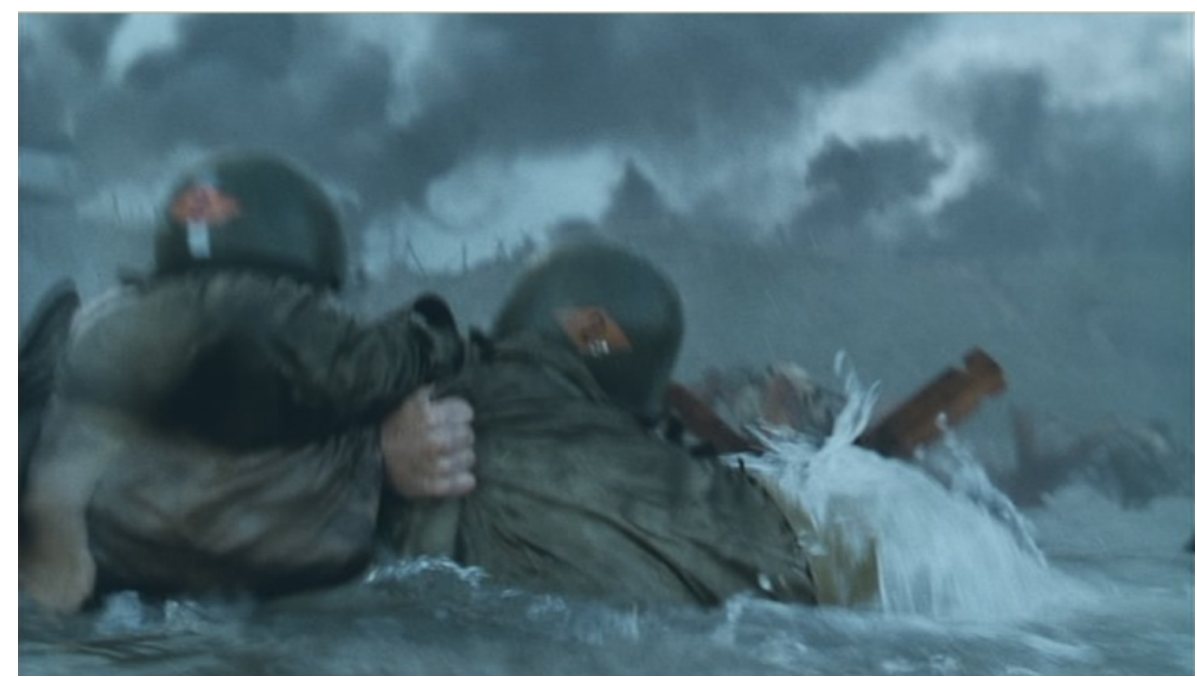

Fonte: O resgate do soldado Ryan, 1998.

Figura 4 - Cenas iniciais do filme "O resgate do soldado Ryan", desembarque na Normandia, no dia D Fotografia: Maikon Matuyama, 18 de set. de 2012

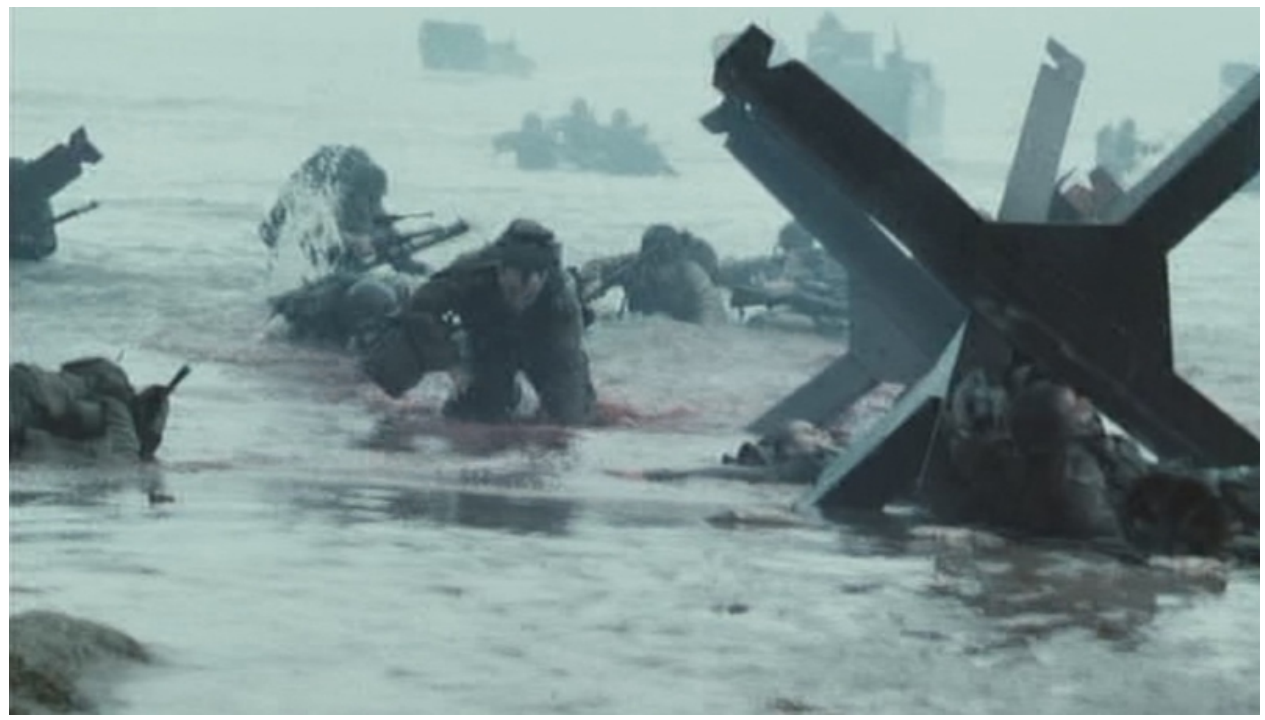

Fonte: O resgate do soldado Ryan, 1998.

O longa-metragem foi apreciado notadamente por seu retrato realístico dos combates da Segunda Guerra Mundial, em particular com a sequência que mostra a chegada na praia, eleita como a "melhor cena de batalha de todos os tempos" pela revista Empire (MATLOCK MERCURY, 2008), além de ter sido qualificada na primeira posição da lista do TV Guide dos "50 Maiores Momentos do Cinema" (TV GUIDE, 2001). A cena custou doze milhões de 
dólares e envolveu mais de 1500 pessoas, diversos deles membros das Forças Reservas de Defesa da Irlanda.

Para transfigurar o elenco em uma unidade militar verossímil, os criadores contaram com o auxílio do Capitão Dale Dye, antigo membro da Marinha. Ele e a equipe de sua empresa Warriors Inc., levaram Hanks e os coadjuvantes Tom Sizemore, Edward Burns, Jeremy Davies, Vin Diesel, Barry Pepper, Giovanni Ribisi e Adam Goldberg para um campo de treinamento militar, onde enfatizavam constantemente sua missão, chamando-os apenas pelos nomes dos personagens.

\section{REPRODUZINDO O VISÍVEL}

Este estudo busca investigar através do filme "O resgate do soldado Ryan" como as fotografias de Robert Capa tiveram sua importância para montagem da cena em questão, e visa descrever quais características desse conjunto de fotografias influíram na estética da montagem do filme na busca de uma construção fidedigna da história.

Assim como a fotografia, o cinema reproduz o visível. Porém, sua noção como documento nem sempre é válida, uma vez que há ficção e que mesmo no gênero documentário existe encenação. Por mais que o aparelho filme o que está diante dele, o que se passa diante da câmera é combinado e encenado, e em filmes de época, lugares, vestimentas e gestos são trabalhados buscando ser verossímeis ao máximo.

Por isso, o cinema é uma arte antropofágica. Devorando os meios que o cercam (teatro, literatura, pintura e fotografia) ele criou sua própria linguagem e se firmou como arte no século XX. De acordo com Walter Benjamin (1996, p. 194), nenhum meio artístico reflete tão claramente este homem e sua compreensão estética de ver o mundo.

\footnotetext{
Mas nada revela mais claramente as violentas tensões do nosso tempo que o fato de que essa dominante tátil prevalece no próprio universo da ótica. É justamente o que acontece no cinema, através do choque de suas sequências de imagens. O cinema se revela assim, também desse ponto de vista, o objeto atualmente mais importante daquela ciência da percepção que os gregos chamavam de estética.
}

O cinema buscou bases para a criação de uma linguagem visual, a do movimento. Gênios como Bazin e Eisenstein contribuíram para a formação da linguagem cinematográfica, já demonstrando o que caracterizaria o futuro da teoria da sétima arte: um conflito de ideias quanto à representação e interpretação de sua imagem, o cinema artístico e o comercial, 
descobrindo que a imagem poderia surtir um efeito muito duradouro. Segundo Carrière (1995, p. 21):

\begin{abstract}
Quase no começo da aventura, os cineastas perceberam que a memória de imagens pode, às vezes, ser mais forte e duradoura do que as palavras e frases. Lembramos o corpo branco de uma mulher, ou um incêndio a bordo de um transatlântico vermelho, de forma muito mais precisa e, provavelmente, mais vívida, do que palavras que descrevam mais ou menos satisfatoriamente aquele corpo ou aquele navio em chamas. Estamos, de qualquer modo, lidando com um outro gênero de memória, completamente diferente, que pode ser partilhada por povos diversos, não importa a língua que eles falem.
\end{abstract}

O que distingue o cinema de todos os outros meios de expressão culturais é o poder excepcional que vem do fato de sua linguagem funcionar a partir da reprodução fotográfica da realidade. Com ele, de fato, são os seres e as próprias coisas que aparecem e falam, dirigem-se aos sentidos e a imaginação: a primeira vista, parece que toda representação (significante) coincide de maneira exata e unívoca com a informação conceitual que veicula (significado) (MARTIN, 2003, p. 18).

\title{
5.1 Descobrindo o Ponto de Vista
}

O movimento, que outrora suscitou o espanto admirativo dos primeiros espectadores, perturbados ao ver as folhas das árvores palpitando sob a brisa ou um trem em sua direção, é certamente o caráter mais específico e mais importante para percepção.

A maioria dos primeiros operadores de cinema estudou no mundo da fotografia, no qual o retrato de frente, seguindo o modelo do teatro à italiana, era a figura mais solicitada. Pouco a pouco o cinema se emancipou da frontalidade sistemática e, quanto mais se avança em sua história, mais fica clara a ideia de filmar um sujeito sob vários ângulos.

O ponto de vista talvez seja o parâmetro mais importante no nível do plano, e isso por pelo menos duas razões: se as câmeras comandadas eletronicamente pudessem ser colocadas no piloto automático, mesmo assim seria preciso que seu operador soubesse ou decidisse em que lugar poderia as instalar e sobre o que apontar a objetiva, Marcel Martin (2003, p. 37) define a escolha do plano a partir da distância da câmera com o objeto:

O tamanho do plano (e consequentemente seu nome e seu lugar na nomenclatura técnica) é determinado pela distância entre a câmera e o objeto e pela duração da cena utilizada. A escolha do plano é condicionada pela clareza necessária a narrativa: deve haver adequação entre o tamanho do plano e seu conteúdo material, por um lado (o plano é tanto maior ou 
próximo quanto menos coisas há para ver), e seu conteúdo dramático, por outro (o tamanho do plano aumenta conforme sua importância dramática ou sua significação ideológica).

Podemos observar que ambas as imagens, tanto as fotografias de Capa, como as imagens do filme, fazem uso do plano conjunto, no qual um ou mais personagens podem ser vistos e identificados facilmente. Assim como no plano geral, este plano serve para contextualizar o local onde ocorrerá todo o resto da cena, assim como para mostrar quais personagens participam desta cena, quais são os enquadramentos em que os artistas têm parte importante porque dominam todos os demais elementos e porque sua fala conta menos com a ajuda dos meios específicos do cinema para ampliá-la e reforçá-la.

Desde os primórdios, e ainda hoje, os diretores usam a colocação da câmara em relação a seus personagens para tentar exprimir significados. Se o seu objetivo consistisse apenas em fazer-nos ver o mundo com maior clareza, bastaria que olhasse as coisas de frente de modo a transmiti-las da maneira mais imparcial possível. Mas não é isso que se passa, pois a intenção da câmera de filmar é ela própria escrever. Coloca-se então inevitavelmente o problema da perspectiva a assumir, do ângulo mais adequado para o que se pretende dizer (MOSCARIELO, 1985, p .29)

As fotografias de Robert Capa, Figuras 1 e 2, caracterizam um leve ângulo de plongê (do francês plongée, "mergulhado"), ou seja, a câmara está colocada acima dos personagens, que são vistos, portanto, em ângulo superior. Esse ângulo é utilizado normalmente para diminiur a força, enfatizar a fragilidade e vunerabilidade dos personagens. No caso das fotografias da guerra, Capa parece priorizar um enquadramento que pudesse agrupar mais elementos.

Nas Figuras 3 e 4, do filme "O resgate do soldado Ryan", Spielberg preferiu fazer uso do ângulo normal, ou seja, a câmera posicionada no nível dos olhos, produzindo planos neutros. A câmera está sempre à altura da cintura dos soldados, o que gera no espectador a sensação de que ele próprio é um soldado à espera de uma bala.

\subsection{Montagem}

A proposta tradicional de montagem no cinema é, entre tantas outras, ordenar as cenas e seus cortes para facilitar a compreensão do que é narrado e a obtenção de recursos visuais (elipses) para transpor as dificuldades narrativas do roteiro.

A montagem é o instrumento dessa consciência ampliada. Na linguagem, supera a sintaxe universal e cria o mais poderoso dos efeitos poéticos. No filme, toma elementos inarticulados ou banais e os funde em idéias ricas 
demais para serem exprimidas por palavras. Em sua melhor forma, a montagem molda essas idéias sentidas em um nosso pensamento e nossa ação. Por si mesma, a montagem não pode realizar essa proeza; devemos ultrapassar a montagem para descobrir as formas e as estruturas mais poderosas e efetivas que o cinema pode utilizar. Mas a montagem permanece o principio vital básico que energiza cada filme que vale a pena e proporciona uma entrada no mundo pré-lógico do pensamento imagístico onde a arte tem suas conseqüências mais profundas (ANDREW, 1989, p. 66).

A montagem do início do filme resulta em um atordoante impacto, graças a uma das sequências de abertura mais intensas, violentas e chocantes do cinema. "O resgate do soldado Ryan” tem um pequeno prólogo, com um homem visitando o túmulo de um certo capitão John Miller, antes de atirar o espectador diretamente na batalha. Segundo Ângelo Moscariello (1985, p. 23) essa descontinuidade de tempo no espaço fílmico, se se dá por uma:

[...] montagem alternada [que] pode muitas vezes produzir uma disparidade tanto espacial como temporal. É o caso das obras desenroladas em dois planos temporais diferentes (presente-passado), caracterizadas por uma intervenção prolongada do procedimento conhecido por flash back. Também neste caso, porém, ambos os níveis temporais se mantêm no interior da matéria da narrativa, quer a transição seja indicada por fondu quer a passagem se faça por corte.

Quando direcionado para a batalha, o espectador se depara com uma montagem incomum no cinema tradicional. A câmera produz imagens tremidas e longas sequências confusas e sem cortes, que transmitem ao público como seria estar naquele local. Para o diretor, a intenção ao produzir as imagens era de transmitir realismo. "Eu não queria fazer o filme como uma produção estilo Hollywood, um extravagante e bruto. Tratava-se de tentar reproduzir as imagens e odores da verdadeira batalha, o verdadeiro combate" (SPIELBERG, 2003).

O espectador é brutalmente jogado no olho de um furacão. As imagens tremidas e as cenas longas sem cortes seguem a estética do documentário, como se sua câmera e o público fossem soldados que descem dos barcos. Novamente, a sensação de confusão causada no espectador se aproxima da confusão causada pelas imagens de Capa, "ligeiramente foras de foco", e que em sequência, possibilitam ao observador produzir mentalmente a sequência nebulosa.

\subsection{Profundidade de Campo}

A profundidade de campo indica a nitidez no sentido do eixo da objetiva. Ao contrário da distância focal, esse parâmetro pertence a experiência cotidiana do ser humano: quando ele fixa sua atenção visual em um objeto bem próximo, o resto do campo tende a se tornar 
borrado. Mas a semelhança entre o olho e a câmera não é perfeita. O olho humano acrescenta a esse fenômeno o desvio entre visão central e visão periférica: não apenas o que se encontra atrás está borrado, mas também o que se encontra dos lados. A menos que recorra a trucagem (uma lente tirando de foco do quadro), o cinema não pode produzir esse efeito, e seus jogos de nitidez imitam muito longinquamente o funcionamento do olho. Segundo Marcel Martin (2003, p. 166), a profundidade de campo tem extrema importância, pois implica uma concepção de direção.

Durante muito tempo, com efeito, a direção em cinema foi concebida como uma mise enscène de teatro (nome que infelizmente herdou), ou seja, o espaço dramático tinha sensivelmente a forma de uma cena de teatro: os personagens "representam" diante de um cenário, colocados sobre uma linha perpendicular ao eixo óptico da câmera e voltados para ela, isto é, para o espectador. Ao contrário, a composição em profundidade de campo é construída em torno do eixo da filmagem, num espaço longitudinal em que os personagens evoluem livremente: o interesse particular desse tipo de direção advém sobretudo do fato de o primeiro plano combinar audaciosamente com o plano geral, acrescentando sua acuidade de análise e sua capacidade de impacto psicológico a presença do mundo e das coisas ao redor, através de enquadramentos de uma rara intensidade estética e humana.

A profundidade de campo favorece eventualmente ambições estéticas e narrativas. Nos primórdios do cinema, essa questão não era colocada, e o objetivo era obter a maior profundidade de campo possível filmando cenas em ambiente fechado com plano fechado ou cenas externas com linhas de fuga, contanto que se dispusesse de uma boa iluminação. Contudo, apesar de ter uma boa iluminação, as fotografias de Capa ficaram ligeiramente fora de foco, enquanto no filme de Spielberg, reproduzindo o efeito, foi usado um leve desfoque mais conhecido no cinema como efeito flu, segundo Umberto Barbaro (1965, p. 137):

Essa proposital falta de nitidez dos contornos dá geralmente um tom especial ao quadro, e consegue um efeito de irrealidade ou certo sabor ambiental: as coisas e as pessoas aparecem banhadas e absorvidas pela atmosfera. Efeito que pode ser particularmente sugestivo, mas não é necessariamente obrigado a limitar-se a uma suavização geral das imagens como alguns parecem crê. Essa suavização é frequentemente usada nas cenas de amor ou para dar graça e leveza a um rosto.

Uma das causas das fotografias de Capa estarem desfocadas pode estar relacionada a condições externas, como, por exemplo, o fato de ele ter que se movimentar muito apressadamente para não ser alvo fácil para balas alemãs e pelo próprio medo e tremor das mãos. Além disso: 
[...] fiquei sabendo que as fotos que eu tinha tirado na "Easy Red" eram as melhores da invasão. Mas o animado assistente do laboratório, ao secar os negativos, havia usado calor demais, e as emulsões derreteram e escorreram diante de todos os olhos do escritório de Londres. Do total de 106 fotos apenas oito se salvaram. As legendas debaixo das fotos borradas pelo calor diziam que as mãos de Capa estavam tremendo muito (CAPA, 2010, p. 198).

No filme, a montagem rápida aliada ao efeito $f l u$ busca difundir no espectador uma sensação de sufocante angústia e desespero, que os soldados enfrentaram para sobreviver naquele desembarque. Essa mesma sensação de angústia pode ser percebida pelo observador das fotografias de Capa, borradas pelo movimento de fuga.

O movimento da câmera é o ultimo parâmetro que intervém na construção do ponto de vista. Em geral, os dois tipos de movimentos de câmera mais utilizados são os panorâmicos, no qual o movimento se dá a partir de uma posição fixa e que pode ser empregado para mostrar o ambiente ou acompanhar o movimento de uma personagem, e os travellings, que têm por objetivo o deslocamento do corpo inteiro no modo retilíneo. A câmara se move para frente, para trás, para os lados, em travelling, e se aproxima e distancia do objeto filmado com recursos da lente, o chamado zoom. A combinação dos movimentos tem a capacidade de, numa única tomada ou plano, passar do plano geral para o plano detalhe, ou vice-versa.

A partir da metade do século XX as câmeras ficaram mais leves e a filmagem com a câmera no ombro ficou mais fácil, inscrevendo movimentos biomecânicos na película pela obliquidade de uma câmera que adere ao seu operador. Na Figura 3 nota-se o uso do travelling para frente só que desta vez mostrando os personagens em primeiro plano e ao fundo a muralha alemã, como na fotografia de Capa (Figura 1). Ambas tem um papel descritivo, mostrando a visão dos soldados americanos ao chegarem na praia.

Na sequência da Figura 4 usa-se o travelling para frente que denota o acompanhamento dos personagens que avançam, sendo importante fazer com que a expressão dos rostos sejam visíveis, expressões também presentes na imagem produzida por Capa (Figura 2).

Contribuindo para a forte sensação de realismo, Spielberg utilizou a abordagem própria dos documentários. Ele não desenhou um prévio storyboard de filmagem e usou a câmera na mão a maior parte do tempo. "Desse modo, pude transitar como um verdadeiro repórter, seguindo os soldados na guerra" (SPIELBERG, 2003), o que aproximou a estética da sequência à estética e composição das fotografias. A câmera na mão produziu imagens com enquadramentos desordenados, e a agitação da câmera proporcionou ao espectador a sensação de fazer parte da cena. 
Um plano que representa homens que carregam com dificuldade um pesado ataúde é agitado por movimentos desordenados: tudo se passa como se tais movimentos, que exprimem o ponto de vista dos homens que carregam o fardo, fosse transferidos para o ponto de vista do espectador, o plano representado não a paisagem que esses homens tem sob olhos, mas sua própria imagem [...]; a câmera, agitada pelo estrondo da explosão, traduz ao mesmo tempo o pânico da multidão e a impressão subjetiva do espectador (MARTIN, 2003, p. 44).

\subsection{Luz e Cor}

A iluminação e a cor participam da narrativa como criadoras de sentido e influenciam o modo como o espectador vai receber e compreender a cena. Um exemplo seriam as cenas de Flashback, que o espectador compreende como tal pelo simples uso do Preto e Branco. A luz pode dramatizar ou divinizar a cena em virtude das conotações ligadas a tradições históricas e aos conceitos de sombra e de luz, enquanto a cor pode cumprir funções psicológicas:

a cor do filme deverá cumprir uma função essencialmente psicológica. Deverá ser, não bela, mas sim significativa. Somente deste modo terá a sua presença uma justificação expressiva e poderá servir para dizer coisas que não poderiam ser ditas sem a sua intervenção. Sempre que tal não acontece, a cor não apenas resulta nociva para a escrita fílmica como corre o risco de empobrecê-la ao ponto de fazê-la regredir para um nível inferior ao alcançado no velho preto e branco (MOSCARIELLO, 1985, p. 39-40).

Além da direção sobre a qual a luminosidade incide sobre o personagem, a própria quantidade de luz pode enriquecer seu retrato psicológico. Segundo Martin Marcel (2003, p. 56) a luz:

Constitui um fator decisivo para a criação da expressividade da imagem. Mas como contribui sobretudo para criar a 'atmosfera', elemento dificilmente analisável, sua importância é desconhecida e seu papel não aparece diretamente aos olhos do espectador desavisado; além disso, a maior parte dos filmes atuais manifesta uma grande preocupação com realismo na iluminação, e tal concepção tende a suprimir seu uso exacerbado e melodramático.

Nas fotografias de Capa e nas imagens do filme é possível notar semelhanças quanto à luminosidade. Em seu livro Robert Capa (2010, p. 186) conta sobre as condições do dia: "era muito cedo ainda e muito cinza para fotos boas, mas a água cinzenta e o céu cinzento tornavam muito interessante a cena dos homenzinhos abaixados atrás dos objetos surrealistas concebidos pela junta de gênios anti-invasão de Hitler".

O diretor de fotografia do filme, Janusz Kaminski, reproduziu a guerra em um pálido tom de verde oliva, que só foi conseguido à custa de manipulação digital. O fotógrafo retirou 
$60 \%$ da cor em laboratório, o que dá às imagens um tom esmaecido, como se elas fossem velhas, e que acentua a percepção climática de nebulosidade do dia D.

A retirada de parte da cor, além de aproximar o filme das fotografias, aumentou o contraste e a sensação de um dia escuro, potencializando a sensação de medo e apreensão sentida pelo público, compondo a aura da sequência, afinal, "não são as imagens que fazem um filme, mas a alma das imagens" (MARTIN, 2003, p. 63).

A estética do "O resgate do Soldado Ryan" deixou uma marca tão profunda em Hollywood que os filmes de guerra vindos a seguir passaram, automaticamente, a ser filmados da mesma maneira, reproduzindo posições de câmera, uso de cores e direção de arte.

\section{5 Áudio}

Enquanto a maioria dos filmes utiliza fundos musicais que dramatizam a cena e sensibilizam o público, o filme em questão não utiliza música na sequência. Os únicos sons são as vozes dos personagens, os efeitos sonoros ou ruídos, os tiros que pipocam de todos os lados da tela e das bombas, aproximando ainda mais a cena do que seria um conflito real, e reforçando o posicionamento do espectador como um dos participantes. Ouve-se apenas sons produzidos pelos elementos que aparecem na tela ou que, sabemos, acham-se nas proximidades, sem que haja nenhuma intenção particular na justaposição imagem-som (MARTIN, 2003, p. 116).

O silêncio é outro fator importante que é exaltado com a ausência das vozes em certo momento da cena, e o seu uso, quando contextualizado dentro de uma estrutura sintática, tem a possibilidade de adquirir significados que podem realçar a importância da continuidade sonora, ou nesse caso pode atuar como um signo, ou seja, representar um mistério, uma dúvida, a morte, a expectativa.

\section{CONSIDERAÇÕES FINAIS}

A fotografia documental, que se constitui a partir de um referente, tornou-se objeto de estudo em diferentes áreas e fonte de pesquisa da cena passada. As imagens do desembarque das tropas aliadas na Normandia, de Robert Capa, abordadas neste estudo, foram utilizadas pelo diretor do filme "O resgate do soldado Ryan" como fonte para reconstruir a cena histórica. Segundo ele, as imagens de Capa são a matriz onde todos vão beber (apud MOURA, 2001, p. 144). 
Para aprofundar a reconstituição das cenas registradas o diretor vai além, e através de um estilo que se aproxima do gênero documental, que inclui cenas longas, confusas, tremidas e sem cortes, recria a aura do que seria uma sequência das imagens de Capa, tremidas e desfocadas. Essa aproximação se dá também na manipulação da cor: enquanto as fotografias de Capa combinam variadas gradações de cinza traduzindo a nebulosidade do dia em questão, Spielberg retira $60 \%$ da cor de suas sequências e manipula o contraste, intensificando as sombras e a sensação climática nebulosa do dia D.

Essa estética diferenciada que até então não era comum no cinema, e a partir de "O resgate do soldado Ryan" virou um paradigma de longas-metragens que retratam conflitos bélicos, culminou no prêmio de melhor direção de fotografia no Oscar do ano de 1999.

A luz, as cores e o cenário aproximaram a representação fílmica dos registros de Capa, enquanto o áudio aproximou ainda mais a cena do que seria um conflito real, reforçando o posicionamento do espectador como um dos participantes.

As imagens de Capa tiveram grande importância para a compreensão e reconstrução da brutalidade da cena de guerra. Na cena inicial do filme, do desembarque na praia de Omaha, o espectador não consegue se sentir indiferente. Não há como não ser tocado por ela, seja pela crueza ou pela violência representada. As sequências e a narrativa, em tom de documentário, não deixam o espectador respirar. A impressão que se buscou passar, através dos recursos cinematográficos como a montagem, o movimento de câmera e o ângulo de tomada, é a mesma de alguém que desembarcou na Normandia naquele dia.

\section{REFERÊNCIAS}

AMBROSE, Stephen E. O dia D, 6 de junho de 1944: a batalha culminante da Segunda Grande Guerra. Tradução de Múcio Bezerra. $6^{\mathrm{a}}$ edição. Rio de Janeiro: Bertrand Brasil, 2005.

ANDREW, J. Dudley. As principais teorias do cinema: uma introdução. Rio de Janeiro: Jorge Zahar Editora, 1989.

BARBARO, Umberto. Elementos de estética cinematográfica. Tradução de Fátima de Sousa. Rio de Janeiro: Editora Civilização Brasileira, 1965.

BEnjamin, Walter. Magia e Técnica, Arte e Política. Tradução de Sérgio Paulo Rouanet. $6^{\text {a }}$ edição. São Paulo: Editora Brasiliense, 1996.

CAPA, Robert. Robert Capa: Fotografia. Tradução de Beatriz Karam Guimarães. São Paulo: Cosac Naify, 2000. 
Naify, 2010.

Ligeiramente fora de foco. Tradução de José Rubens Siqueira. São Paulo: Cosac

CARRIÈRE, Jean-Claude. A linguagem secreta do cinema. Tradução de Fernando Albagli, Benjamin Albagli. Rio de Janeiro: Nova Fronteira, 1995.

HEMINGWAY, Ernest. Viagem à vitória. VEJA, São Paulo, jun. 1944, caderno especial. Disponível em: $<$ http://www.veja.abril.com.br/especiais_online/

segunda_guerra/edicao007/pontodevista.shtml>. Acesso em: 19 set. 2012.

KOSSOY, Boris. Fotografia e história. São Paulo: Ática, 1989.

MAGNUM PHOTOS. Acervo fotográfico. Disponível em:

$<$ http://www.magnumphotos.com>. Acesso em: 18 set. 2012.

MARTIN, Marcel. A linguagem cinematográfica. Tradução de Paulo Neves. São Paulo: Editora Brasiliense, 2003.

MOURA, Flávio. Algo de novo no front. VEJA, São Paulo, ano , n.1.692, p.142-145, 21 mar. 2001. Disponível em:<http://www.veja.abril.com.br/210301/p_142.html>. Acesso em: 19 set. 2012.

MOSCARIELLO, Ângelo. Como ver um filme. Lisboa: Editorial Presença, 1985.

ROARING, back to the forties. Matlock Mercury. 6 ago. 2008. Disponível em :< http://www.matlockmercury.co.uk/news/local-news/roaring-back-to-the-forties-1-869125>. Acessado em: 25 jul. 2012.

THE 50 GREATEST MOVIE MOMENTS. TV guide. 24 mar. 2001. Disponível em:< http://www.filmsite.org/tvguidemoments4.html>. Acessado em 13 ago. 2012.

SPIELBERG, Steven. O resgate do soldado Ryan. Estados Unidos. Paramount, 2003. 1 DVD (169 min), NTSC, color. Título original: Saving Private Ryan.

WHELAN, Richard. Introdução. In: CAPA, Cornell. Robert Capa: fotografias. Tradução de Beatriz Karam Guimarães. São Paulo: Cosac Naify, 2000. p.10.

Original recebido em: 17/09/2013

Aceito para publicação em: 10/11/2013

\section{Sobre os autores}

Maikon Nikken Matuyama

Bacharel em audiovisual pelo Centro Universitário Barão de Mauá (CBM). 
Especialista em Fotografia pela Universidade Estadual de Londrina (UEL).

\section{Maria Luisa Hoffmann}

Jornalista e Mestre pela Universidade Estadual de Londrina (UEL). Doutoranda pela Universidade de São Paulo (ECAUSP). Professora convidada da Especialização em Fotografia na Universidade Estadual de Londrina (UEL). Docente da Graduação em Comunicação Social na Universidade do Oeste Paulista (UNOESTE). Faz parte da Comissão Editorial da Revista Discursos Fotográficos (UEL). 